\title{
40 Years of Neuroepidemiology
}

The year 2022 marks two years of the COVID 19 pandemic. The battle is still on, and as we fight, we lean on the support of epidemiological studies to help us understand and minimize the burden of this disease that has already taken the lives of over 5.2 million people worldwide.

Despite being a respiratory viral disease, the SARS$\mathrm{CoV}-2$ has been associated with many neurological complications. The COVID 19 pandemic is also challenging our mental health due to social isolation and the general feeling of uncertainty. The impact of the psychological and neurological burden of COVID 19 is shown to be more and more critical as new findings and data are published. As we learn more about this disease and its longterm sequelae, monitoring the epidemiology of these symptoms is crucial to the advancements in the treatment and prevention of the disease. All relevant COVID 19 related research and data published in Neuroepidemiology and other Karger's journals have been shared with Free Access in our Topic Article Package: Coronavirus (COVID-19) ${ }^{1}$.

Neuroepidemiology was founded in 1982 by B.S. Schoenberg, as clinical neurosciences started an exciting phase and had the opportunity to initiate preventive practice $^{2}$. The journal's aim was to accelerate clinical advances in the treatment and care of patients with neurological diseases by providing the scientific community with a fo-

\footnotetext{
1 Topic Article Package: Coronavirus (COVID-19) (2021, November 30). Retrieved from https://www.karger.com/tap/Home/278492

2 Schoenberg B.S. The Scope of Neuroepidemiology: from Stone Age to Stockholm. Neuroepidemiology 1982;1:1-16 (DOI: 10.1159/000110685)
}

rum for the collection and debate of accurate estimates of neurological diseases distribution. In 2022 we celebrate 40 years of Neuroepidemiology, which is still to date the only journal entirely devoted to the Epidemiology of Neurological Diseases. Neuroepidemiology has fundamentally contributed for four decades as a source of quality research findings from renowned international scientists, clinicians, and early career researchers. Since then, we have published 55 volumes with contributions from more than 2360 co-authors across 88 countries.

After four decades, Neuroepidemiology is today one of the leading journals in the field of epidemiology of neurology worldwide. In acknowledgment of this milestone, in 2022, we will publish specially invited papers in a celebratory anniversary section that will focus on the development of epidemiology of stroke, neurodegenerative diseases, dementia, epilepsy, and others. The celebratory section will be published with free access to reach a broad audience. All issues published in the jubilee volume will feature a specially created logo on their cover.

The current success of the publication is the product of the leadership of Prof. Valery Feigin, Neuroepidemiology's Editor-in-Chief since 2008, as well as of a collective effort. And we would like to take this opportunity to thank our associate editors and editorial board members, past and present, authors, reviewers, readers, and staff, for their continued commitment to providing a reputable forum for discussion in neuroepidemiology.

Gabriella Karger, Chairwoman and Publisher Daniel Ebneter, CEO karger@karger.com

www.karger.com/ned

Karger! (c) 2022 S. Karger AG, Basel

(2022 S. Karger AG, Basel 